\title{
Coronary Vasculitis Induced in Mice by the Cell Wall Mannoprotein of Candida krusei
}

\author{
Chiho Yanai, ${ }^{a}$ Hiroaki Tanaka, ${ }^{a, b}$ Noriko N. Miura ${ }^{c}$ Ken-ichi Ishibashi, ${ }^{a}$ Daisuke Yamanaka, ${ }^{a}$ \\ Hiroaki Ohnishi, ${ }^{d}$ Naohito Ohno, ${ }^{* a}$ and Yoshiyuki Adachi*,a \\ ${ }^{a}$ Laboratory for Immunopharmacology of Microbial Products, School of Pharmacy, Tokyo University of \\ Pharmacy and Life Sciences; 1432-1 Horinouchi, Hachioji, Tokyo 192-0392, Japan: ${ }^{b}$ Department of Pharmacy, \\ Kyorin University Hospital; 6-20-2 Shinkawa, Mitaka, Tokyo 181-8611, Japan: ${ }^{c}$ Center for Pharmaceutical \\ Education, School of Pharmacy, Tokyo University of Pharmacy and Life Sciences; 1432-1 Horinouchi, Hachioji, \\ Tokyo 192-0392, Japan: and ${ }^{d}$ Department of Laboratory Medicine, Kyorin University School of Medicine; 6-20-2 \\ Shinkawa, Mitaka, Tokyo 181-8611, Japan.
}

Received December 4, 2019; accepted March 4, 2020; advance publication released online March 10, 2020

\begin{abstract}
Kawasaki disease (KD) is an inflammatory disease that was identified by Professor Tomisaku Kawasaki in 1961. Candida albicans-derived substances, such as the hot water extract of $C$. albicans (CADS) and Candi$d a$ water-soluble fraction (CAWS), induced coronary vasculitis similar to KD in mice. An increasing proportion of deep-seated candidiasis cases are caused by non-albicans Candida and are often resistant to antifungal drugs. We herein investigated whether the hot water extract of $C$. krusei, inherently resistant to fluconazole, induces vasculitis in mice. Three strains of $C$. $k r u s e i$, NBRC1395, NBRC1162, and NBRC10737, were cultured in natural (Y) and chemically defined (C) media and cell wall mannoprotein (MN) fractions were prepared by autoclaving cells (CKY1395MN, CKC1395MN, CKY1162MN, CKC1162MN, CKY10737MN, and CKC10737MN). All MN fractions reacted strongly with Concanavalin A (Con A) and dectin-2 and induced anaphylactoid shock in ICR mice. MNs induced severe coronary vasculitis in DBA/2 mice, resulting in cardiac hypertrophy. MNs also induced coronary vasculitis in $\mathrm{C57} \mathrm{Bl} / 6 \mathrm{mice}$. These results suggest that the MNs of non-albicans Candida, such as $C$. krusei, induce similar toxicity to those of $C$. albicans.
\end{abstract}

Key words Candida krusei; vasculitis; dectin-2; innate immunity; mannoprotein

\section{INTRODUCTION}

Kawasaki disease (KD) is an inflammatory disease that typically develops in children, particularly those younger than 4 years old, and was identified by Professor Tomisaku Kawasaki in 1961. ${ }^{1-3)}$ Typical symptoms include fever, swelling of the lips, throat, and lymph nodes, and peeling of the skin on the hands and feet. KD is prevalent in Asian countries including Japan. The number of KD patients has continued to increase annually. Although intravenous immunoglobulin (IVIG) is applied as the initial treatment, between 10 and $20 \%$ of patients develop coronary vasculitis and, thus, have an increased risk of cardiovascular disease during their lifetime., ${ }^{4,5)}$ Despite extensive research, the etiology of KD remains unclear. Recent advances have increased the accuracy of diagnoses and resulted in the development of therapeutic strategies for better acute as well as long-term outcomes. ${ }^{6-10)}$

We and others reported that Candida albicans-derived substances (CADS) and the C. albicans water-soluble fraction (CAWS) induced coronary vasculitis similar to $\mathrm{KD}$ in mice. ${ }^{11-34)}$ Previous studies demonstrated the contribution of various factors to the induction of CAWS-vasculitis, including the induction of Th17 cells, activation of the interleukin-1 $\beta$ (IL-1 $\beta$ ) pathway, changes in the microbiome, CCL2 production, CCR2-, CXCL9-, and CXCL10-dependent signaling, LPA-LPA1 signaling, the mannan-binding lectin (MBL)dependent complement pathway, and the contribution of the vasa vasorum. ${ }^{1-25)}$

CAWS-vasculitis, particularly in DBA/2 mice, is severe and ultimately results in death due to cardiac hypertrophy. ${ }^{23,32)}$ The progression of CAWS arteritis in DBA/2 mice has been classified into the following three stages: 1) the development of vasculitis, 2) complex myocardial remodeling with hypertrophy, and 3) fatal severe left ventricular dysfunction and sudden death. The series of changes associated with CAWS-vasculitis are characterized as chronic inflammatory diseases, possibly due to irreversible reactions.

CAWS was prepared from the culture supernatant of $C$. albicans NBRC1385 cultured at $27^{\circ} \mathrm{C}$ for $2 \mathrm{~d}$ in C-limiting medium. Under these culture conditions, the $\mathrm{pH}$ of the medium was started at 5.2 and was gradually acidified to 2.3 during cultivation. We precisely analyzed optimum culture conditions, and the fraction prepared at $27^{\circ} \mathrm{C}$ under neutral culture conditions (CAWS727) contained a higher amount of $\beta$-mannosyl links and did not induce vasculitis or anaphylactoid shock. ${ }^{23,24)}$ To confirm the $\mathrm{pH}$ as well as culture temperature, mannoprotein fractions ( $\mathrm{MN}$ fractions) were also prepared from the hot water extract and sodium hydroxide extract of cells of C. albicans NBRC1385 cultured in C-limiting medium or natural medium. Similar to CAWS, vasculitis and anaphylactoid shock were induced by all fractions, except for that prepared from cells cultured at $27^{\circ} \mathrm{C}$ under neutral culture conditions. ${ }^{31)}$

Mannans are the major antigen of Candida cell walls and are species specific. Typing sera have been developed to immunochemically diagnose Candida spp. The biosynthesis of mannoproteins is controlled by the activation of various enzyme genes, such as PMTs, MNNs, and OCH1. ${ }^{35-50)}$ The 
resulting mannoproteins contain $\mathrm{N}$-linked mannan, O-linked mannan, and phosphodiester-linked mannan moieties. CAWS is the polysaccharide fraction released into the culture supernatant of $C$. albicans NBRC1385 cultured in C-limiting medium and is mainly composed of the mannoprotein $\beta$-glucan complex. ${ }^{26)}$ Mannan in CAWS consists of the main chain of $\alpha$-1.6-mannose with a side chain of $\alpha-1.2$-mannnose and $\alpha-1.3$ mannnose.

Acquired and innate immunities both function cooperatively in the host-pathogen interaction. Polysaccharide components of the fungal cell wall, such as $\beta$-glucan, chitin, and mannan, are pathogen-associated molecular patterns (PAMPs) ${ }^{51-55)}$ Mannan is also known as a species- and straindependent antigen. Receptors for mannan, such as the mannose receptor, mannan-binding protein, and dectin-2, have been extensively examined. Dectin-2 is a type II transmembrane C-type lectin receptor (CLR) that is the most abundantly expressed on tissue macrophages and inflammatory monocytes. Dectin-2 lacks a signaling motif within its short cytoplasmic domain, but associates with the Fc-receptor gamma $(\mathrm{FcR} \gamma)$ chain. $\mathrm{FcR} \gamma$ contains sequences of the immunoreceptor tyrosine-based activation motif (ITAM). Knockout mice of dectin-2, the innate immune receptor for mannan, were recently shown to be resistant to CAWS-vasculitis. ${ }^{13)}$

Although C. albicans is the most prevalent species involved in mucocutaneous and disseminated infections, the incidence of candidiasis due to non-albicans Candida spp. is increasing, ${ }^{56-62)}$ among which C. glabrata, C. tropicalis, C. parapsilosis, and C. krusei are the major isolates. These species are inherently resistant or acquire resistance, or both, to commonly used antifungal drugs, such as fluconazole, and, thus, the identification of species of Candida is important for selecting therapeutic strategies. Since the mannoprotein structures of $C$. albicans and non-albicans Candida differ, their toxicological as well as biological activities may also differ.

In 1980, Kurtzman et al. proposed C. krusei as the asexual form (anamorph) of the corresponding sexual form (teleomorph) of Pichia kudriavzevii. ${ }^{63)}$ This was subsequently confirmed by sequencing of the $26 \mathrm{~S}$ ribosomal DNA of the type strains of $C$. krusei and P. kudriavzevii. Strains of P. kudriavzevii are widely distributed in nature, and often encountered in spontaneous fermentation and used to produce traditional fermented foods. Recent studies strongly suggested that clinically isolated strains are the same as environmental isolates. ${ }^{60)}$ However, it currently remains unclear whether the extract of C. krusei induces coronary vasculitis.

To examine the relationship between MN structures and vasculitis, we attempted to prepare extracellular MN fractions from several Candida strains; however, the yield of the extracellular fractions significantly differed in a strain-dependent manner (data not shown). In parallel with this approach, we prepared cell wall MN fractions from C. albicans NBRC1385 and demonstrated similarities in vasculitis and anaphylactoid shock induced by these fractions and by CAWS. ${ }^{31)}$ Therefore, for screening purposes, the cell wall $\mathrm{MN}$ fraction is better for obtaining a sufficient quantity from various species. In the present study, we prepared MN fractions from 3 strains of $C$. krusei and examined anaphylactoid shock and coronary vasculitis induced by these fractions.

\section{MATERIALS AND METHODS}

Materials Tween 20 was purchased from Wako Pure Chemical Corporation (Osaka, Japan). Mannan from Saccharomyces cerevisiae was from Sigma-Aldrich (St. Louis, MO, U.S.A.).

Strains Strains of C. albicans NBRC1385 and C. krusei NBRC1395, NBRC1162, and NBRC10737 were purchased from the Biological Resource Center, NITE (NBRC), stored at $25^{\circ} \mathrm{C}$ on Sabouraud agar (Difco, U.S.A.), and passaged once every 3 months.

Culture Media YPD medium contained the following (per liter): $10 \mathrm{~g}$ yeast extract, $20 \mathrm{~g}$ Bacto peptone, and $20 \mathrm{~g}$ D-glucose (final $\mathrm{pH}, 5.2$ ). C-limiting medium, originally described by Shepherd and Sullivan, was used to grow Candida spp. C-limiting medium contained the following (per liter): $10 \mathrm{~g}$ sucrose, $2 \mathrm{~g}\left(\mathrm{NH}_{4}\right)_{2} \mathrm{SO}_{4}, 2 \mathrm{~g} \mathrm{KH}_{2} \mathrm{PO}_{4}, 0.05 \mathrm{~g} \mathrm{CaCl}_{2} \cdot 2 \mathrm{H}_{2} \mathrm{O}$, $0.05 \mathrm{~g} \mathrm{MgSO}_{4} \cdot 7 \mathrm{H}_{2} \mathrm{O}, 1 \mathrm{mg} \mathrm{ZnSO}_{4} \cdot 7 \mathrm{H}_{2} \mathrm{O}, 1 \mathrm{mg} \mathrm{CuSO} \cdot 5 \mathrm{H}_{2} \mathrm{O}$, $0.01 \mathrm{~g} \mathrm{FeSO}_{4} \cdot 7 \mathrm{H}_{2} \mathrm{O}$, and $25 \mu \mathrm{g}$ biotin at a final $\mathrm{pH} 5.2 .^{24,31)}$

Preparation of CAWS CAWS was prepared from $C$. albicans strain NBRC1385 in accordance with conventional methods. ${ }^{24)}$ The procedure used was as follows: $5 \mathrm{~L}$ of medium (C-limiting medium) was added to a glass incubator and cultured at $27^{\circ} \mathrm{C}$ for $2 \mathrm{~d}$ with air supplied at a rate of $5 \mathrm{~L} / \mathrm{min}$ and rotation at $400 \mathrm{rpm}$. Following the culture, an equal volume of ethanol was added, and after the mixture was allowed to stand overnight, the precipitate was collected. The precipitate was suspended in $250 \mathrm{~mL}$ of distilled water, and the solubilized fraction was collected. Ethanol was added to the solubilized fraction and the mixture was left to stand overnight. The precipitate was collected and dried with acetone to obtain CAWS.

Preparation of the Cell Wall MN Fraction C. albicans NBRC1385 and C. krusei NBRC1395, NBRC1162, and NBRC10737 were inoculated into YPD medium $(250 \mathrm{~mL} \times 2$ bottles) and cultured at $37^{\circ} \mathrm{C}$ for $2 \mathrm{~d}$ with reciprocal shaking. Each strain was also inoculated into $\mathrm{C}$-limiting medium $\left(250 \mathrm{~mL} \times 2\right.$ bottles) and cultured at $27^{\circ} \mathrm{C}$ for $2 \mathrm{~d}$. To stop the growth of Candida, an equal volume of ethanol was added and the culture was left to stand overnight. Candida cells were collected by centrifugation and washed with distilled water. Candida cells were again suspended in distilled water and the $\mathrm{MN}$ fraction was extracted at $128^{\circ} \mathrm{C}$ for $4 \mathrm{~h}$. After centrifugation, the supernatant was lyophilized and the precipitate was dried by ethanol and acetone.

Physicochemical Analysis Total carbohydrate concentrations were measured using the phenol-sulfuric acid method with D-glucose as the standard. Total protein concentrations were assessed using the BCA Protein Assay Regent kit (PIERCE Biotechnology) with bovine serum albumin as the standard.

Microplate Assays for Detecting Mannoproteins a) Ninety-six-well half area microplates (Greiner bio-one) were coated with CAWS, mannan, or MN fractions dissolved in bicarbonate buffer ( $\mathrm{pH}$ 9.8). After blocking by $1.0 \%$ BSA/PBST, serially diluted Concanavalin A peroxidase conjugate (Con A-POX) was added and incubated. After extensive washing, plate-bound Con A was detected by TMB reagent (Tetramethylbenzidine MicroWell Peroxidase Substrate System (Kirkegaard \& Perry Laboratories)).

b) Ninety-six-well half area microplates (Greiner Bioone) were coated with CAWS, mannan, or $\mathrm{MN}$ fractions 
$(25 \mu \mathrm{g} / \mathrm{mL})$, dissolved in $0.1 \mathrm{M}$ phosphate buffer, and incubated at $4^{\circ} \mathrm{C}$ for $24 \mathrm{~h}$. After blocking by $1.0 \%$ BSA/PBST (with $\mathrm{Ca} / \mathrm{Mg}$ ), serial dilutions of recombinant h-dectin-2 conjugated with the human immunoglobulin (Ig)-Fc fragment (Sino Biological) were added (maximum concentration of $1.0 \mu \mathrm{g} / \mathrm{mL}$ ). After the incubation, anti-human IgG-POX was added to detect recombinant dectin-2. After extensive washing, platebound dectin-2 was detected by TMB reagent.

Mice Male ICR, Balb/c, C57Bl/6, and DBA/2 mice were purchased from Japan SLC. Mice were maintained under specific pathogen-free (SPF) conditions at $23 \pm 1^{\circ} \mathrm{C}$ with a constant humidity of $55 \pm 5 \%$ under a 12-h light/dark cycle, and had free access to food (CE-2) and tap water according to the Guidelines for Experimental Animal Care issued by the Prime Minister's Office of Japan. Mice were used in the present study at 5 weeks of age. All animal experiments followed the guidelines of laboratory animal experiments by Tokyo University of Pharmacy and Life Sciences (TUPLS), and each of the experimental protocols was approved by the Committee of Laboratory Animal Experiments in TUPLS (P15-42).

Assay for the Anaphylactoid Reaction The indicated doses of the MN fractions and CAWS were intravenously (i.v.) administered to ICR mice. The incidence and severity of rapid anaphylactoid shock were assessed within $30 \mathrm{~min} .{ }^{24}$

Administration Schedule for the Induction of Coronary Vasculitis After a 1-week acclimation period with each diet, the MN fractions and CAWS were administered intraperitoneally (i.p.) for five consecutive days to each mouse in order to measure survival or vasculitis. To assess vasculitis, the hearts of animals were fixed with $10 \%$ neutral formalin and prepared in paraffin blocks. Tissue sections were stained with hematoxylin-eosin (H\&E). ${ }^{24)}$

Statistical Analysis Results are expressed as means and the standard deviation (S.D.). The significance of differences between means was measured using the Student's $t$-test. Survival rates were analyzed using the Kaplan-Meier method, and the significance of differences was analyzed using the Log-rank test.

\section{RESULTS}

Preparation of MN Fractions of C. krusei Strains Cultured in Natural and Synthetic Media The induction of coronary vasculitis in mice was originally demonstrated by Murata in 1978 by injecting CADS obtained from a Kawasaki disease patient. Naoe and Takahashi repeatedly investigated
CADS-induced coronary vasculitis from the view point of pathology. We demonstrated that CAWS induced a similar pathology in mice. We also confirmed that coronary vasculitis was induced by the hot water extract ( $\mathrm{MN}$ fraction) of the standard strain C. albicans NBRC1385. In the analysis of vasculitis induced by other Candida spp., C. albicans NBRC1385 was selected as the reference strain in the present study. $\mathrm{MN}$ fractions of $C$. albicans NBRC1385 were prepared from cells cultured for $2 \mathrm{~d}$ in $\mathrm{C}$-limiting medium $\left(27^{\circ} \mathrm{C}\right)$ and YPD medium $\left(37^{\circ} \mathrm{C}\right)$, as described previously. ${ }^{31)}$ Each extract was named CAC1385MN and CAY1385MN, respectively. Both MN fractions contained approximately $30 \%$ proteins assessed by the bicinchoninic acid (BCA) method (Table 1). Three strains of C. krusei, NBRC1162, NBRC1395, and NBRC10737, were obtained from NBRC and used in the present study. To prepare $\mathrm{MN}$ fractions, each strain was cultured in either YPD or C-limiting medium for $48 \mathrm{~h}$ with reciprocal shaking, and washed cell suspensions were autoclaved at $128^{\circ} \mathrm{C}$ for $4 \mathrm{~h}$. After centrifugation, the supernatant fraction was lyophilized. The resulting MN fractions were designated as follows: CKY1162MN, CKC1162MN, CKY1395MN, CKC1395MN, CKY10737MN, and CKC10737MN. The yields, elemental analysis, and carbohydrate and protein contents of $\mathrm{MN}$ fractions are summarized in Table 1.

The yields of MN fractions were higher in YPD medium (approx. $250 \mathrm{mg} / 250 \mathrm{~mL}$ culture). Similar results were obtained in the elemental analysis of both culture media. Quantitative analyses revealed that the MN fractions contained approximately $55-80 \%$ carbohydrates.

Anaphylactoid Shock Induced by MN Fractions of $C$. krusei CAWS induced acute anaphylactoid shock in mice when injected i.v. based on visual inspections and survival. ${ }^{24)}$ Shock was not induced in C5-deficient mice, but was induced by the activation of complement pathways and resulting production of anaphylatoxins. To compare toxicity, MN fractions were administered i.v. to ICR mice ( $400 \mu \mathrm{g} / \mathrm{mouse})$ and visually inspected to obtain the shock score. As shown in Table 1, almost all mice treated with the $\mathrm{MN}$ fractions of C. krusei died with a strong phenotype.

Induction of Vasculitis by MN Fractions of C. krusei The progression of CAWS arteritis in DBA/2 mice was classified into the following three stages: 1) the development of vasculitis, 2) complex myocardial remodeling with hypertrophy, and 3) fatal severe left ventricular dysfunction and sudden death. Vasculitis activity was assessed using the same system previously established by CAWS research. CAWS, CAC1385MN,

Table 1. Yield and Properties of MN Fractions of C. krusei Strains

\begin{tabular}{|c|c|c|c|c|c|c|c|c|}
\hline Strain & Culture media & Abbreviation & $\begin{array}{c}\text { Extract } \\
\text { (MN fraction) }\end{array}$ & Residue & $\begin{array}{c}\mathrm{C} / \mathrm{H} / \mathrm{N} \\
(\%)\end{array}$ & $\begin{array}{c}\text { Carbohydrate } \\
(\%)\end{array}$ & $\begin{array}{l}\text { Protein } \\
(\%)\end{array}$ & $\begin{array}{c}\text { Acute toxicity } \\
\text { dead/total }\end{array}$ \\
\hline C. albicans NBRC1385 & YPD & CAY1385MN & 164.5 & 487.5 & $38.8 / 6.3 / 9.3$ & 64.2 & 28.6 & $2 / 3$ \\
\hline C. krusei NBRC1162 & YPD & CKY1162MN & 230.3 & 493.6 & $40.7 / 6.5 / 9.0$ & 58.1 & 29.8 & $3 / 3$ \\
\hline C. krusei NBRC1395 & YPD & CKY1395MN & 243.7 & 529.4 & $40.5 / 6.5 / 9.3$ & 80.7 & 27.3 & $3 / 3$ \\
\hline C. krusei NBRC10737 & YPD & CKY10737MN & 256.5 & 506.4 & $41.0 / 6.5 / 8.5$ & 55.4 & 19.4 & $3 / 3$ \\
\hline C. albicans NBRC1385 & C-limit & CAC1385MN & 293.25 & 292.5 & $40.5 / 6.5 / 8.3$ & 51.2 & 30.3 & $1 / 3$ \\
\hline C. krusei NBRC1162 & C-limit & CKC1162 MN & 125.2 & 166.8 & $40.9 / 6.7 / 8.6$ & 68.5 & 30.9 & $2 / 3$ \\
\hline C. krusei NBRC1395 & C-limit & CKC1395MN & 156.2 & 168.4 & $41.7 / 6.6 / 9.9$ & 64.4 & 42.9 & $3 / 3$ \\
\hline C. krusei NBRC10737 & C-limit & $\mathrm{CKC} 10737 \mathrm{MN}$ & 136.5 & 154.8 & $40.6 / 6.5 / 9.0$ & 69.7 & 30.4 & $3 / 3$ \\
\hline
\end{tabular}

Values shown in Extract and Residue were mg/250 mL culture. Values of CAY1385MN and CAC1385MN were quoted from Tada's and Yanai's publications (Refs. 31, 33). 


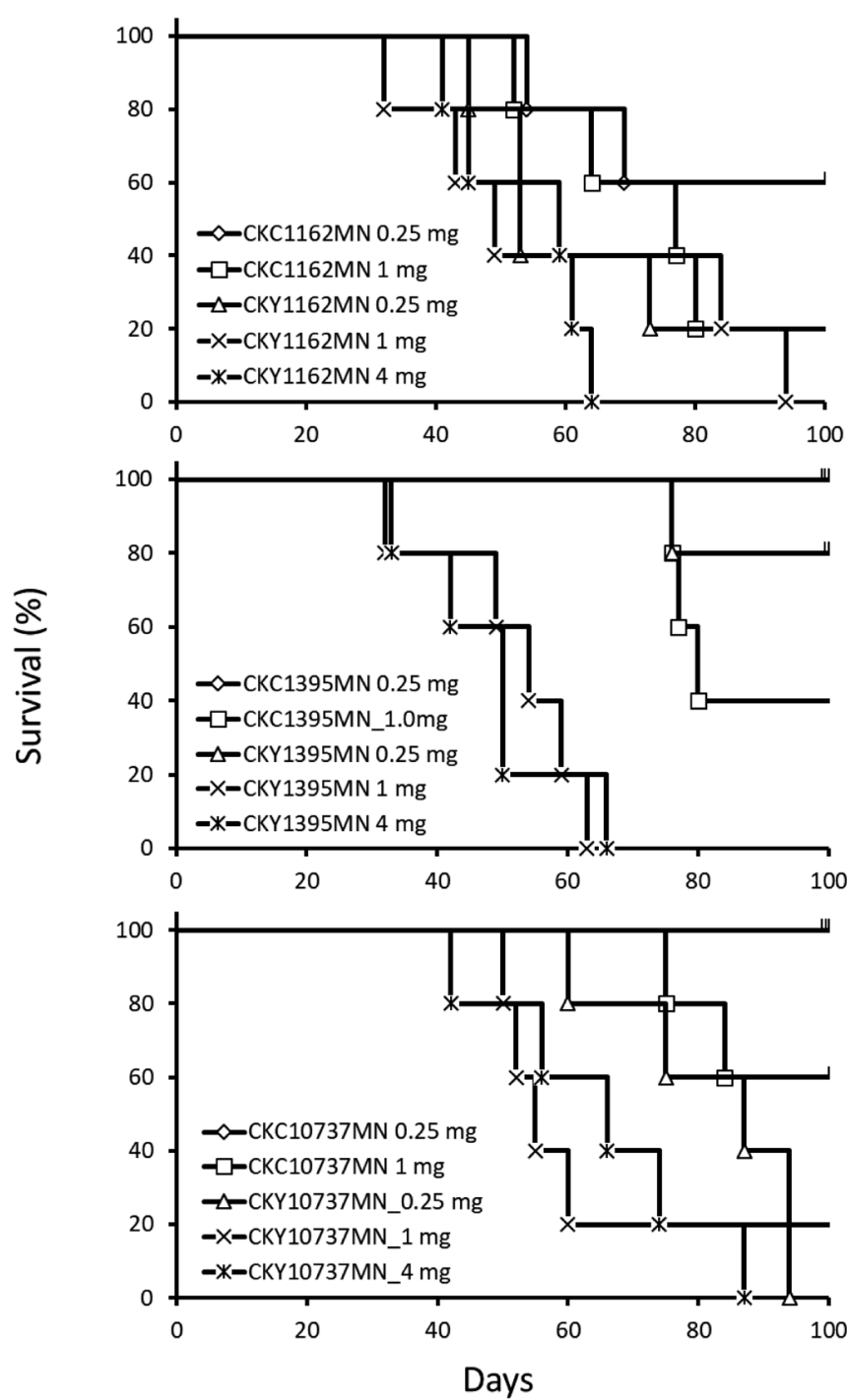

Fig. 1. Survival of MN Fraction-Administered Mice

Survival time of MN fraction-administered mice. MN fractions were prepared under 2 culture conditions, C-limiting and YPD media, using three strains of $C$. krusei. MN fractions were administered to DBA/2 mice $(n=5)$ for 5 consecutive days and survival was observed $100 \mathrm{~d}$ after the last day of the MN fraction administration. Doses of $0.25,1.0$, and $4 \mathrm{mg}$ were used.

and CAY1385MN were used as the positive control. Repeated experiments showed that the minimum dose of CAWS needed to induce vasculitis was $0.25 \mathrm{mg} /$ mouse $\times 5$. MN fractions were administered to DBA/2 mice $(n=7), 2$ mice treated with each fraction were sacrificed on day 28 , and the histology of the aorta was examined by H\&E staining. The remaining mice $(n=5)$ were continuously housed and survival, body weight, and heart weight were measured.

Figure 1 shows the survival of each mouse administered $\mathrm{MN}$ fractions of $0.25,1$, or $4 \mathrm{mg} / \mathrm{mouse}$ during $100 \mathrm{~d}$ of observation. Table 2 summarized the number of alive mice on day 100 and the mean survival days of each group. At a dose of $4 \mathrm{mg}$, all mice administered CKY1162MN, CKY1395MN, and CKY10737MN died. At a dose of $1 \mathrm{mg}$, YPD-cultured MN fractions exhibited stronger activity with a higher death rate and fewer mean survival days than C-limiting-cultured $\mathrm{MN}$ fractions. The survival days of these groups were significant. At a dose of $0.25 \mathrm{mg}$, mean survival days of CKY1395MN, CKY1162MN, and CKY10737MN were 96, 65, and 82, re-
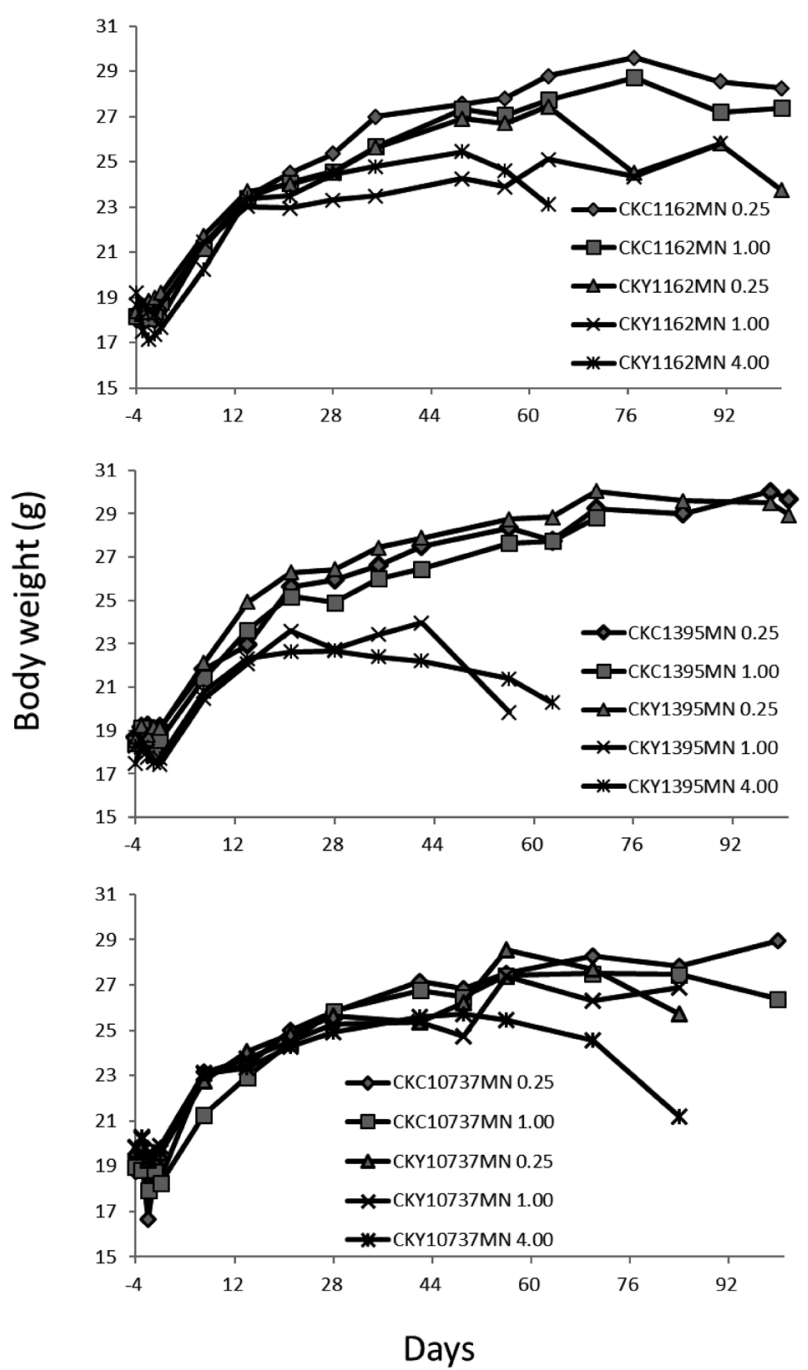

Fig. 2. Changes in Body Weights of MN Fraction-Administered Mice

Body weight changes in $\mathrm{MN}$-administered mice. All experimental data were the same as those shown in the legend of Fig. 1.

spectively. The survival days of CKY1162MN administered group were statistically significantly shorter than other 2 groups $(p<0.05)$. In contrast, no mice died following the administration of CKC1395MN $(0.25 \mathrm{mg})$ and CKC10737MN $(0.25 \mathrm{mg})$. These results showed that YPD-cultured MN fractions exhibited stronger activity and significantly shorter mean survival days. In contrast, vasculitis activity of $\mathrm{MN}$ fractions among three strains were similar in each other. Compared the mean survival days of $\mathrm{MN}$ fractions from C. krusei and $C$. albicans, activities are rather stronger in C. krusei.

Figure 2 shows body weight changes during the induction of vasculitis. Table 2 summarized the number of alive mice and the mean body weight at 8 weeks (day 56). CKY1395MN and CKY1162MN resulted in significantly lighter body weights. Although CKY10737MN did not induce significant differences in body weight, many mice died after 8 weeks, suggesting weaker activity in the three extracts.

Figure 3 shows vasculitis induced by CAWS, CAC1385MN, and CAY1385MN. One mg of CAWS or MN fractions was i.p. administered to $\mathrm{DBA} / 2$ mice $(n=3)$ for 5 consecutive days, and tissue sections were prepared after 3 weeks and stained with H\&E. In this experiment, CAWS induced panvasculitis. In contrast, CAC1385MN (2 out of 3 mice) and 
CAY1385MN (1 out of 3 mice) both induced vasculitis, but not pan-vasculitis. A summary of the histological examination of each heart section was shown in Table 3. Vasculitis was indicated as "Score" as follows: stained specimens were carefully examined for inflammatory lesions of the vessel wall under a light microscope. The score was calculated as the sum of 5 segments, i.e., left coronary artery, right coronary artery, left coronary sinus, right coronary sinus, and non-coronary sinus. The degree of inflammation in each segment was assessed as: $0=$ no inflammation, $1=$ inflammation in the intima or adventitia, $2=$ inflammation in the intima and adventitia, and 3 =inflammation in all layers of the vascular wall (i.e., pan-vasculitis). The maximum and minimum scores of each mouse were 15 and 0 , respectively. Comparisons of the scores of CAWS, CAC1385MN, and CAY1385MN revealed that the vasculitis of CAWS was the most severe (Table 3, Experiment No. 1).

Figure 4 shows H\&E staining data on the aorta and coronary region of $\mathrm{MN}$ fraction-injected mice that were randomly selected on day 28 from each experimental group, as shown
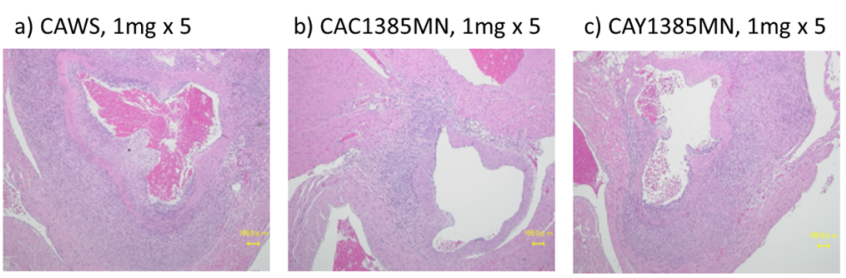

Bar indicate $100 \mu \mathrm{m}$

Fig. 3. H\&E Staining of the Aortic Area of $C$. albicans FractionAdministered DBA/2 Mice

CAWS, CAC1385MN, or CAY1385MN (1 mg/mouse) was administered i.p. to DBA/2 mice $(n=3)$ for 5 consecutive days. Three weeks after the last administration, the hearts of DBA/2 mice were fixed in buffered formalin solution, embedded in paraffin, thin-sectioned, and stained with H\&E. Each section was analyzed by microscopy and a representative section was shown for each fraction. (Color figure can be accessed in the online version.) in Figs. 1 and 2. Table 3 shows the score of vasculitis in two mice. In all sections, $1395 \mathrm{Y} 0.25,1395 \mathrm{Y} 1.0,1395 \mathrm{Y} 4.0$, $1162 \mathrm{C} \_0.25,1162 \mathrm{C} \_1.0,1162 \mathrm{Y} \_1.0,1162 \mathrm{Y} \_4.0,10737 \mathrm{Y} \_0.25$, $10737 \bar{Y} \_1.0$, and $10 \overline{7} 37 \mathrm{Y} \_4.0$ showed the severe infiltration of leukocytes and a thick vascular wall representative of vasculitis (Table 3, Experiment Nos. 2-1, 2-2, 2-3).

Table 4 shows the heart weights of surviving mice, which were all higher than $250 \mathrm{mg}$, suggesting hypertrophy (the heart weights of control mice were approximately $180 \mathrm{mg}$ ). Based on these results, all MN fractions of C. krusei induced vasculitis, with that caused by MN fractions prepared in YPD medium being more severe.

As described in Introduction, the severity of CAWS vasculitis depended on the strains of mice. $\mathrm{C} 57 \mathrm{Bl} / 6$ and $\mathrm{BALB} / \mathrm{c}$ mice are the most frequently used inbred strains for immunological research and the establishment of gene knockout mice. ${ }^{12-15)}$ $\mathrm{C} 57 \mathrm{Bl} / 6$ mice are less sensitive to CAWS-induced vasculitis than DBA/ 2 mice and a dose of $1-2 \mathrm{mg} \times 5$ of CAWS is generally administered. In the present study, vasculitis induced by CAC1385MN, CAY1385MN, and CKY1395MN $(4 \mathrm{mg} \times 5)$ was examined $(n=3)$ and the results obtained showed that that CAY1385MN (2 out of 3 mice) and CKY1395MN (2 out of 3 mice) induced significant activity (Table 3, Experiment No. 3). CAC1385MN did not induce vasculitis under these experimental conditions. The induction of vasculitis by CKY1395MN was also tested using the BALB/c strain and the results obtained revealed that all mice tested had severe vasculitis (3 out of 3 mice). Therefore, the MN fractions of $C$. krusei showed similar vasculitis activity to that of CAWS.

Chemical and Biochemical Properties of MN Fractions of $\boldsymbol{C}$. krusei The proton NMR spectra of MN fractions in D2O were measured and shown in Figs. 5a and b. CAY1385MN and CAC1385MN were shown as references. The six spectra of MN fractions of C. krusei in Fig. 5 were similar to each other, particularly the anomeric area of mannan, between 4.9 and $5.3 \mathrm{ppm}$. The spectral pattern was

Table 2. Mean Survival Days of MN Fraction Administered DBA/2 Mice

\begin{tabular}{|c|c|c|c|c|c|c|}
\hline \multirow[b]{2}{*}{ Group_dose } & \multicolumn{3}{|c|}{ Survival days ${ }^{b)}$} & \multicolumn{3}{|c|}{ Body weight at 8 weeks } \\
\hline & No. of alive mice on day 100 & Mean \pm S.D. & $p$-Value ${ }^{c)}$ & No. of alive mice at 8 weeks & Mean \pm S.D. & $p$-Value ${ }^{c)}$ \\
\hline CAC1385MN_4.0 $0^{a)}$ & 4 & $85.8 \pm 24.1$ & & & & \\
\hline CAY1385MN_4.0 $0^{a)}$ & 3 & $94.8 \pm 12.4$ & & & & \\
\hline CKC1162MN_0.25 & 3 & $85.2 \pm 22.3$ & & 5 & $27.8 \pm 2.49$ & \\
\hline CKC1162MN_1.00 & 1 & $74.8 \pm 18.4$ & & 5 & $27.16 \pm 1.74$ & \\
\hline CKY1162MN_0.25 & 1 & $65 \pm 22.6$ & $* *$ & 3 & $26.7 \pm 1.05$ & \\
\hline CKY1162MN_1.00 & 0 & $60.4 \pm 27.0$ & $* *$ & 2 & $23.9 \pm 0.14$ & $*$ \\
\hline CKY1162MN_4.00 & 0 & $54 \pm 10.3$ & $* * *$ & 3 & $24.6 \pm 1.92$ & $*$ \\
\hline CKC1395MN_0.25 & 5 & $101 \pm 0.0$ & & 5 & $28.46 \pm 0.95$ & \\
\hline CKC1395MN_1.00 & 2 & $87 \pm 12.9$ & & 5 & $27.6 \pm 1.56$ & \\
\hline CKY1395MN_0.25 & 4 & $96 \pm 11.2$ & & 5 & $28.86 \pm 1.01$ & \\
\hline CKY1395MN_1.00 & 0 & $51.4 \pm 12.1$ & $* * *$ & 2 & $19.95 \pm 0.07$ & $* * *$ \\
\hline CKY1395MN_4.00 & 0 & $48.2 \pm 12.2$ & $* * *$ & 1 & $21.4 \pm$ & $* *$ \\
\hline CKC10737MN_0.25 & 5 & $101 \pm 0.0$ & & 5 & $27.5 \pm 2.45$ & \\
\hline CKC10737MN_1.00 & 3 & $92.4 \pm 12.2$ & & 5 & $27.4 \pm 1.49$ & \\
\hline CKY10737MN_0.25 & 0 & $82 \pm 14.5$ & & 5 & $28.5 \pm 1.97$ & \\
\hline CKY10737MN_1.00 & 1 & $63.6 \pm 21.2$ & $* *$ & 2 & $27.4 \pm 0.99$ & \\
\hline CKY10737MN_4.00 & 0 & $65 \pm 17.1$ & $* *$ & 3 & $25.5 \pm 1.36$ & \\
\hline
\end{tabular}

a) Data from Tada et al. (Ref. 31). b) Days of survived mice were shown as 101. c) $p$-Values; compared with all survived group. *, $p<0.05, * *<0.01, * * *<0.001$. 
Table 3. Summary of the Vasculitis Score of MN Fractions Shown in This Study

\begin{tabular}{|c|c|c|c|c|c|}
\hline Experiment No. & Fraction name & Dose $(\mathrm{mg}) \times 5$ & Mouse & $N=$ & Score of each mouse \\
\hline \multirow[t]{3}{*}{1.} & CAWS & 1 & $\mathrm{DBA} / 2$ & 2 & 15,15 \\
\hline & CAC1385MN & 1 & $\mathrm{DBA} / 2$ & 3 & $0,3,15$ \\
\hline & CAY1385MN & 1 & $\mathrm{DBA} / 2$ & 3 & $2,2,10$ \\
\hline \multirow[t]{5}{*}{$2-1$} & $\mathrm{CKC} 1162 \mathrm{MN}$ & 0.25 & $\mathrm{DBA} / 2$ & 2 & 6,15 \\
\hline & CKC1162MN & 1 & $\mathrm{DBA} / 2$ & 2 & 6,7 \\
\hline & CKY1162MN & 0.25 & $\mathrm{DBA} / 2$ & 2 & 0,0 \\
\hline & CKY1162MN & 1 & $\mathrm{DBA} / 2$ & 2 & 3,15 \\
\hline & CKY1162MN & 4 & $\mathrm{DBA} / 2$ & 2 & 9,15 \\
\hline \multirow[t]{5}{*}{$2-2$} & CKC1395MN & 0.25 & $\mathrm{DBA} / 2$ & 2 & 0,0 \\
\hline & CKC1395MN & 1 & $\mathrm{DBA} / 2$ & 2 & 1,1 \\
\hline & CKY1395MN & 0.25 & $\mathrm{DBA} / 2$ & 2 & 0,9 \\
\hline & CKY1395MN & 1 & $\mathrm{DBA} / 2$ & 2 & 15,15 \\
\hline & CKY1395MN & 4 & $\mathrm{DBA} / 2$ & 2 & 15,15 \\
\hline \multirow[t]{5}{*}{$2-3$} & CKC10737MN & 0.25 & $\mathrm{DBA} / 2$ & 2 & 0,1 \\
\hline & CKC10737MN & 1 & $\mathrm{DBA} / 2$ & 2 & 0,0 \\
\hline & CKY10737MN & 0.25 & $\mathrm{DBA} / 2$ & 2 & 3,2 \\
\hline & CKY10737MN & 1 & $\mathrm{DBA} / 2$ & 2 & 15,15 \\
\hline & CKY10737MN & 4 & $\mathrm{DBA} / 2$ & 2 & 15,15 \\
\hline \multirow[t]{4}{*}{$3-1$} & CAC1385MN & 4 & $\mathrm{C} 57 \mathrm{Bl} / 6 \mathrm{j}$ & 3 & $0,0,1$ \\
\hline & CAY1385MN & 4 & $\mathrm{C} 57 \mathrm{Bl} / 6 \mathrm{j}$ & 3 & $3,9,15$ \\
\hline & CKY1395MN & 4 & $\mathrm{C} 57 \mathrm{Bl} / 6 \mathrm{j}$ & 3 & $1,6,15$ \\
\hline & CKY1395MN & 4 & $\mathrm{BALB} / \mathrm{c}$ & 3 & $15,15,15$ \\
\hline
\end{tabular}

Vasculitis score of each mouse was calculated as follows. The stained specimens were carefully examined for inflammatory lesions of the vessel wall under a light microscope. Score was calculated as sum of 5 segments, i.e., left coronary artery, right coronary artery, left coronary sinus, right coronary sinus, and non-coronary sinus. The degree of inflammation in each segment was assessed as: $0=$ no inflammation, $1=$ inflammation in the intima or adventitia, $2=$ inflammation in the intima and adventitia, and $3=$ inflammation in all layers of the vascular wall (i.e., panvasculitis). The maximum and minimum score are 15 and 0 , respectively.

significantly different from that of C. albicans NBRC1385 already reported by Tada et al. ${ }^{31)}$ The ${ }^{1} \mathrm{H}-\mathrm{NMR}$ spectra of $C$. krusei mannan were previously reported by Kobayashi et al. and Kogan et al. and suggested the presence of $\alpha-1,2-, \alpha-1,3-$, and $\alpha-1,6$-mannose links. ${ }^{64-67)}$ The spectral patterns shown in Fig. 5 were similar to those in their studies and consistent with these findings. Furthermore, some signals assignable to $\beta$-1,6-glucan were present (4.5 ppm). Based on these results, $\mathrm{MN}$ fractions were mainly composed of the mannan specific to C. krusei.

The mannan components of each $\mathrm{MN}$ fraction were further characterized by reactivity to dectin- 2 and Con A, which are well-known lectins that are specific for $\alpha$-mannose. Enzymelinked immunosorbent assay (ELISA) plates were coated with $\mathrm{MN}$ fractions and reactivities to dectin-2 and Con A were assessed by serial dilutions of these lectins. Figures $6 a$ and $b$ show the reactivities of the MN fractions of the YPD culture, while Figs. $6 \mathrm{c}$ and d show those of the C-limiting culture. Figures $6 \mathrm{a}$ and $\mathrm{c}$ show reactivity to dectin-2, and Figs. $6 \mathrm{~b}$ and $\mathrm{d}$ that to Con A. In each figure, dotted lines show the reference polysaccharides CAWS, CAY1385MN, and CAC1385MN, and solid lines show MN fractions of C. krusei. In comparisons of strain differences, the MN fraction of strain 1395 always exhibited the strongest activity for both dectin-2 and Con A. In a comparison of culture media, the strain difference was high in C-limiting media.

\section{DISCUSSION}

In the present study, we examined whether non-albicans
Candida induce coronary vasculitis similar to CAWS-vasculitis by using C. krusei strains NBRC1162, 1395, and 10737. These strains were cultured in YPD or C-limiting medium, and $\mathrm{MN}$ fractions were prepared by autoclaving washed cells. All MN fractions reacted with Con A and dectin-2, and induced anaphylactoid shock and vasculitis. The results obtained for survival rates showed that vasculitis induced by MN fractions cultured in YPD medium was more severe. Therefore, not only $C$. albicans, but also non-albicans Candida induced coronary vasculitis. In comparisons of vasculitis activity between culture media, the MN fractions of YPD exhibited significantly stronger activity than the C-limiting-cultured fraction assessed by the survival days (Table 2), the vasculitis score (Table 3), as well as the heart weight of survived mice (Table 4). In comparison of vasculitis activities among strains, slight differences were exhibited in some activities, such as the number of survivors on day 100 and the mean survival days of CKY_025 groups (Table 2). However, MN fractions were crude polysaccharide fractions and contained protein part and the ratio were varied in each other, thus, detailed examination might be needed to use highly purified cell wall mannan fractions of these strains.

The structure of Candida mannan varies significantly in a species-dependent manner. It has been characterized by typing sera, and the relevant structure was recently analyzed in detail using NMR. ${ }^{64,65)}$ The structure of C. krusei was also examined by NMR spectroscopy, and major links were characterized as $\alpha-1,2-, \alpha-1,3-$, and $\alpha-1,6$-mannose links; however, a precise characterization has not yet been conducted. ${ }^{66-68)}$ In the present study, we demonstrated the clear reactivities of 

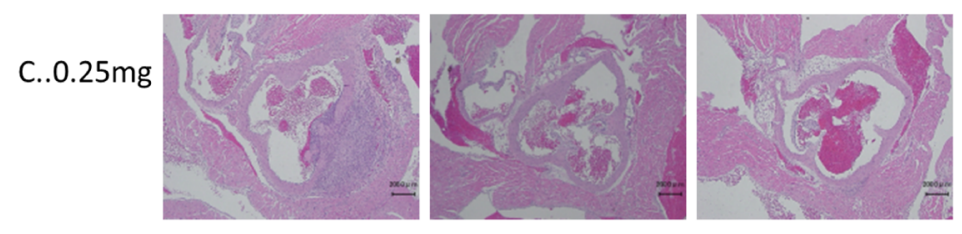

C..1.0mg
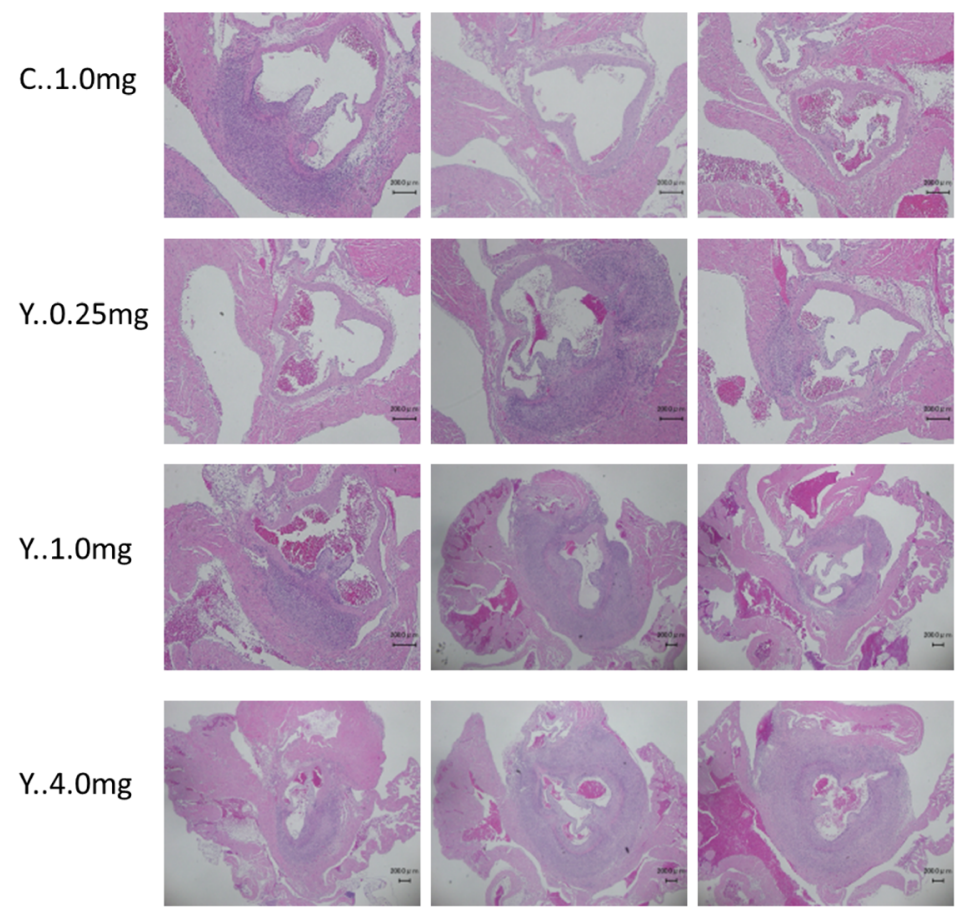

Fig. 4. H\&E Staining of the Aortic Area of DBA2 Mice Administered C. krusei-Derived MN Fractions

MN fractions were prepared under 2 culture conditions, C-limiting and YPD media, using three strains of $C$. krusei. MN fractions were administered to DBA/2 mice $(n=7)$ for 5 consecutive days and, on day 28 , the hearts of DBA/2 mice ( 2 mice each) were fixed in buffered formalin solution, embedded in paraffin, thin-sectioned, and stained with H\&E. Each section was analyzed by microscopy and a representative section was shown for each MN fraction. A summary of H\&E staining was shown in Table 3. (Color figure can be accessed in the online version.)

Table 4. Heart Weight of Survived Mice on Day 100

\begin{tabular}{cccc}
\hline \hline \multirow{2}{*}{ Media } & 1162 & 1395 & 10737 \\
\cline { 2 - 4 } & Mean \pm S.D. & Mean \pm S.D. & Mean \pm S.D. \\
\hline C-Limit..0.25 mg & $294.1 \pm 100.1$ & $257.7 \pm 10.2$ & $259.8 \pm 41.9$ \\
C-Limit.1.0 mg & $248.8 *$ & $325.1 \pm 6.0$ & $427.2 \pm 48.4$ \\
YPD..0.25 mg & $508.9 *$ & $374.5 \pm 156.4$ & $* *$ \\
YPD..1.0 mg & $* *$ & $* *$ & $* *$ \\
YPD..4.0 mg & $* *$ & $* *$ & $* *$ \\
\hline
\end{tabular}

*, survived one mouse. ${ }^{*}$, survived no mouse.

MN fractions to Con A and dectin-2, suggesting biochemical and biological similarities in $\mathrm{MN}$ fractions between C. albicans and C. krusei.

We previously prepared CAWS under several culture conditions. ${ }^{24)}$ The fraction CAWS727 prepared using C-limiting medium at $27^{\circ} \mathrm{C}$ and $\mathrm{pH} 7.0$ did not induce vasculitis or anaphylactoid shock. An NMR analysis of CAWS727 indicated the presence of $\beta$-1,2-linked manno-oligosaccharides, suggesting the production of antigen structure 6 under these conditions. Based on these results, factor 6 is a negative structure inducing vasculitis and anaphylactoid shock. In the NMR spectra of the MN fractions of $C$. krusei, none of the $\beta$-linked mannose signals were detected, which supports the induction of severe vasculitis by $C$. krusei.

CAWS induced both acute anaphylactoid shock and vasculitis. CAWS activates the lectin pathway of complement, and, thus, acute anaphylactoid shock is induced by subsequent degranulation events. CAWS is a ligand for dectin-2, and Oharaseki previously demonstrated that the dectin-2 knockout mouse was resistant to CAWS-vasculitis. ${ }^{13)}$ In the present study, we showed the strong reactivity of $\mathrm{MN}$ fractions to dectin-2. These results strongly suggest that MN fraction-induced vasculitis is also mediated through dectin-2 signaling. Signaling by dectin- 2 is mediated by the cross-linking of Fc $\gamma \mathrm{R}$ and subsequent intracellular signaling, and then induces the local and systemic activation of innate immunity. ${ }^{51-55)}$ Dectin-2 
a

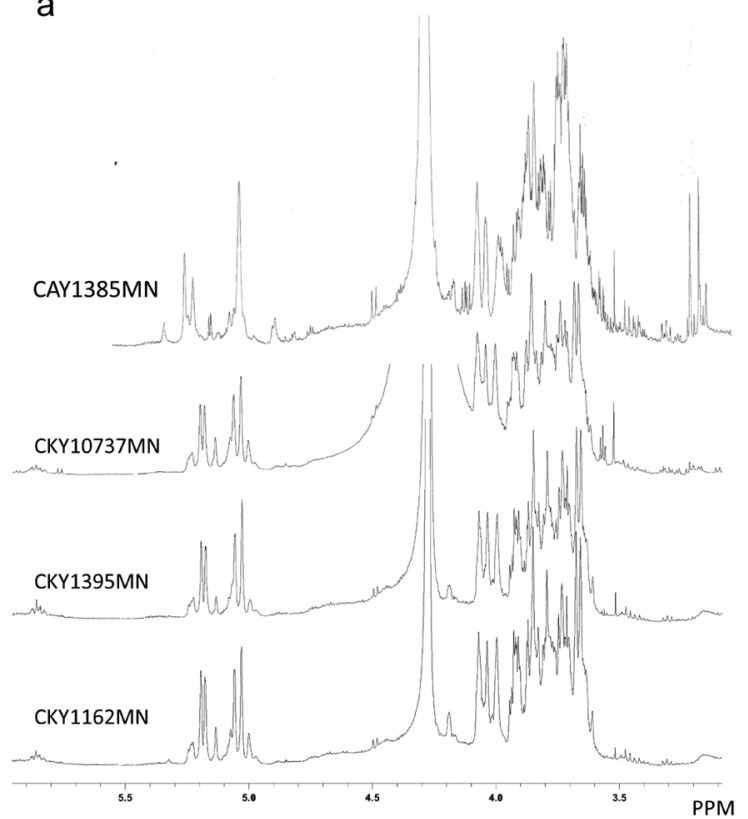

b

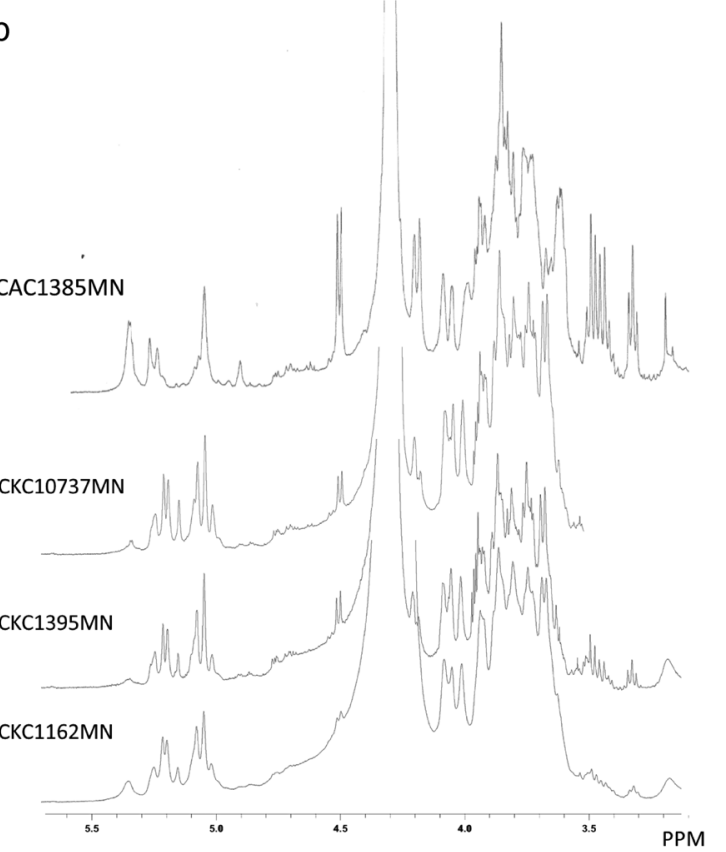

Fig. 5. ${ }^{1} \mathrm{H}-\mathrm{NMR}$ Spectra of MN Fractions of C. krusei

The 1D- ${ }^{1} \mathrm{H}-\mathrm{NMR}$ spectra of MN fractions prepared by 3 strains of C. krusei (NBRC 1162、NBRC1395, NBRC10737) cultured in C-limiting medium and YPD medium were measured. All spectra were recorded in D2O at $343 \mathrm{~K}$ using a Bruker Advance 500 spectrometer. MN fractions of C. albicans NBRC1385 (CAC1385MN and CAY1385MN) were measured as a reference. Chemical shifts are reported in ppm relative to acetone-d6 as an internal standard $(\delta \mathrm{H}=2.189 \mathrm{ppm})$. a) $\mathrm{MN}$ fractions of $\mathrm{YPD}$ medium, b) MN fractions of C-limiting medium.

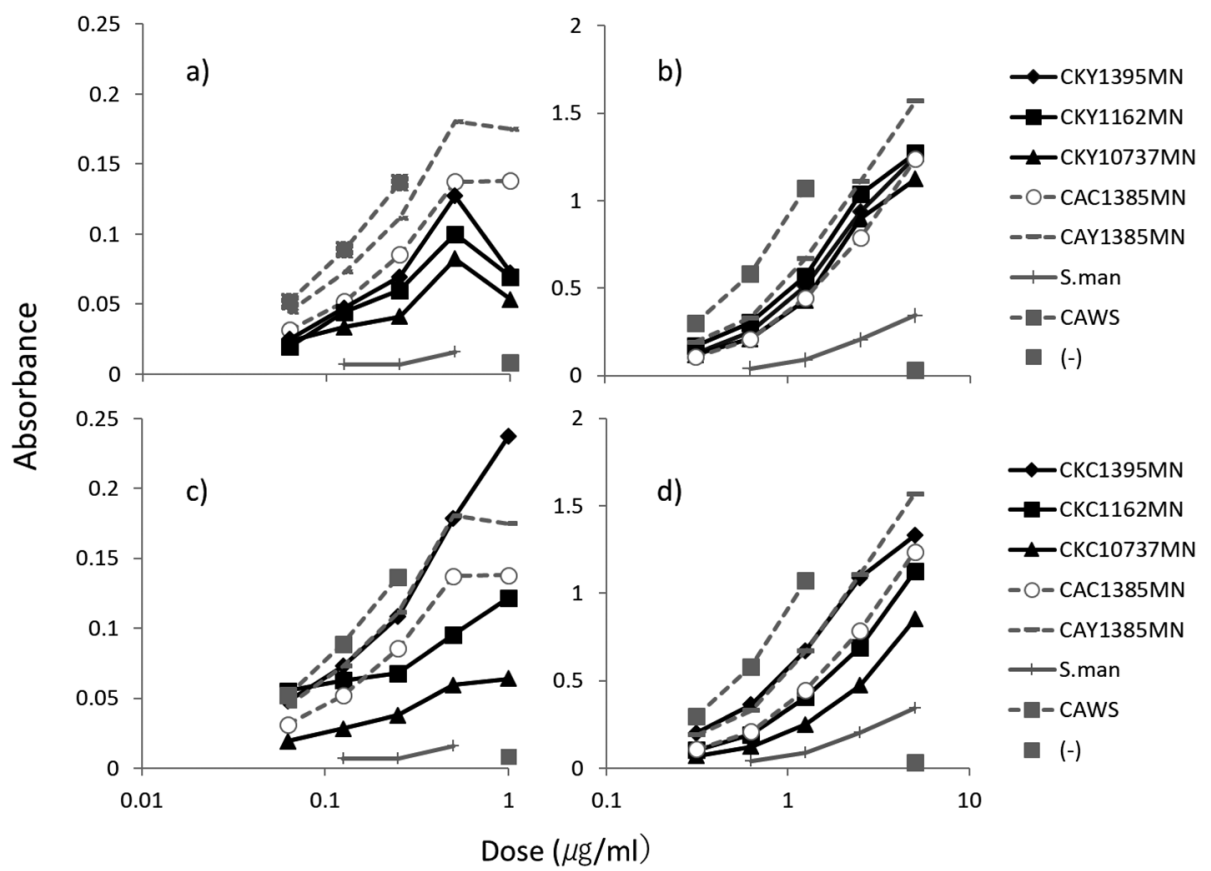

Fig. 6. Reactivities of CAWS, Mannan, and MN Fractions of C. albicans and C. krusei to Dectin-2 or ConA

a, c; Ninety-six-well half area microplates (Greiner bio-one) were coated with CAWS, mannan, and MN fractions of C. albicans and C. krusei dissolved in bicarbonate buffer ( $\mathrm{pH}$ 9.8). After blocking by $1.0 \%$ BSA/PBST (with $\mathrm{Ca} / \mathrm{Mg}$ ), serially diluted solutions of recombinant h-dectin-2 conjugated with the human Ig-Fc fragment (Sino Biological) were added (maximum concentration, $1.0 \mu \mathrm{g} / \mathrm{mL}$ ). After the incubation, anti-human IgG-POX was added to detect recombinant dectin-2. After extensive washing, plate-bound dectin-2 was detected by TMB reagent. b, d; Ninety-six-well half area microplates (Greiner bio-one) were coated with CAWS, mannan, and the MN fractions of C. albicans and C. krusei dissolved in bicarbonate buffer (pH 9.8). After blocking by 1.0\% BSA/PBST, serially diluted Con A-POX was added and incubated. After extensive washing, plate-bound Con A was detected by TMB reagent (Tetramethylbenzidine MicroWell Peroxidase Substrate System (Kirkegaard \& Perry Laboratories)).

dependency is also supported by the mannan-rich fraction prepared by the deproteinization of MN fractions (CAY1385 and CAC1385) by sodium hypochlorite oxidation and exhibiting significant vasculitis activity (data not shown). ${ }^{34)}$

The incidence of candidiasis due to non-albicans Candida spp. is increasing. ${ }^{56-59)}$ These species are resistant to commonly used antifungal drugs, such as fluconazole. Azole resistance is also becoming more prevalent due to the use of related chemicals as pesticides. C. krusei is one of the major isolates of non-albicans Candida. It is the asexual form (anamorph) of 
the corresponding sexual form (teleomorph) of $P$. kudriavzevii. Strains of $P$. kudriavzevii are recognized as fermenting, not pathogenic, fungi, are widely distributed in nature, and are often encountered in spontaneous fermentations and used to produce traditional fermented foods. ${ }^{60-63)}$ Recent studies strongly suggested that clinical and environmental strains are similar. In the present study, the pathological activities of anaphylactoid shock and induction of coronary vasculitis by $\mathrm{MN}$ fractions of $C$. krusei were similar to those of $C$. albicans. Since the population of developed countries is aging, and the number of immunocompromised individuals is increasing, not only in hospitals, but also in the community, extensive efforts are required to prevent, manage, and diagnose non-Candida infections.

Conflict of Interest The authors declare no conflict of interest.

\section{REFERENCES}

1) Kawasaki $T$, Singh S. Kawasaki disease-the journey over 50 years: 1967-2017. Int. J. Rheum. Dis., 21, 7-9 (2018).

2) Kawasaki T. Kawasaki disease. Int. J. Rheum. Dis., 17, 597-600 (2014).

3) Kawasaki T, Naoe S. History of Kawasaki disease. Clin. Exp. Nephrol., 18, 301-304 (2014).

4) Ferdosian F, Dastgheib SA, Morovati-Sharifabad M, Lookzadeh MH, Noorishadkam M, Mirjalili SR, Akbarian-Bafghi MJ, Neamatzadeh H. Cumulative evidence for association between IL-10 polymorphisms and Kawasaki disease susceptibility: a systematic review and meta-analysis. Fetal Pediatr. Pathol., (2019). doi: $10.1080 / 15513815.2019 .1686789$

5) Kobayashi T, Saji T, Otani T, et al. Efficacy of immunoglobulin plus prednisolone for prevention of coronary artery abnormalities in severe Kawasaki disease (RAISE study): a randomised, open-label, blinded-endpoints trial. Lancet, 379, 1613-1620 (2012).

6) Yamaji N, da Silva Lopes K, Shoda T, Ishitsuka K, Kobayashi T, Ota E, Mori R. TNF-alpha blockers for the treatment of Kawasaki disease in children. Cochrane Database Syst. Rev., 8, CD012448 (2019).

7) Kone-Paut I, Cimaz R, Herberg J, Bates O, Carbasse A, Saulnier JP, Maggio MC, Anton J, Piram M. The use of interleukin 1 receptor antagonist (anakinra) in Kawasaki disease: a retrospective cases series. Autoimmun. Rev., 17, 768-774 (2018).

8) Onouchi Y, Tamari M, Takahashi A, Tsunoda T, Yashiro M, Nakamura Y, Yanagawa H, Wakui K, Fukushima Y, Kawasaki T, Nakamura Y, Hata A. A genomewide linkage analysis of Kawasaki disease: evidence for linkage to chromosome 12. J. Hum. Genet., 52, 179-190 (2007).

9) Onouchi Y, Gunji T, Burns JC, et al. ITPKC functional polymorphism associated with Kawasaki disease susceptibility and formation of coronary artery aneurysms. Nat. Genet., 40, 35-42 (2008).

10) Onouchi Y, Onoue S, Tamari M, et al. CD40 ligand gene and Kawasaki disease. Eur. J. Hum. Genet., 12, 1062-1068 (2004).

11) Miyabe C, Miyabe Y, Nagai J, Miura NN, Ohno N, Chun J, Tsuboi R, Ueda H, Miyasaka M, Miyasaka N, Nanki T. Abrogation of lysophosphatidic acid receptor 1 ameliorates murine vasculitis. Arthritis Res. Ther., 21, 191 (2019).

12) Miyabe C, Miyabe Y, Bricio-Moreno L, Lian J, Rahimi RA, Miura NN, Ohno N, Iwakura Y, Kawakami T, Luster AD. Dectin2-induced CCL2 production in tissue-resident macrophages ignites cardiac arteritis. J. Clin. Invest., 129, 3610-3624 (2019).

13) Oharaseki T, Yokouchi Y, Enomoto Y, Sato W, Ishibashi K, Miura N, Ohno N, Takahashi K. Recognition of alpha-mannan by dectin
2 is essential for onset of Kawasaki disease-like murine vasculitis induced by Candida albicans cell-wall polysaccharide. Mod. Rheumatol., 30, 350-357 (2020).

14) Suzuki C, Nakamura A, Miura N, Fukai K, Ohno N, Yahata T, Okamoto-Hamaoka A, Fujii M, Yoshioka A, Kuchitsu Y, Ikeda K, Hamaoka K. Non-receptor type, proline-rich protein tyrosine kinase 2 (Pyk2) is a possible therapeutic target for Kawasaki disease. Clin. Immunol., 179, 17-24 (2017).

15) Miyabe C, Miyabe Y, Komiya T, Shioya H, Miura NN, Takahashi K, Ohno N, Tsuboi R, Luster AD, Kawai S, Miyasaka N, Nanki T. A sphingosine 1-phosphate receptor agonist ameliorates animal model of vasculitis. Inflamm. Res., 66, 335-340 (2017).

16) Nakamura A, Okigaki M, Miura N, Suzuki C, Ohno N, Kametani $\mathrm{F}$, Hamaoka K. Involvement of mannose-binding lectin in the pathogenesis of Kawasaki disease-like murine vasculitis. Clin. Immunol., 153, 64-72 (2014).

17) Oharaseki T, Yokouchi Y, Yamada H, Mamada H, Muto S, Sadamoto K, Miura N, Ohno N, Saji T, Naoe S, Takahashi K. The role of TNF-alpha in a murine model of Kawasaki disease arteritis induced with a Candida albicans cell wall polysaccharide. Mod. Rheumatol., 24, 120-128 (2014).

18) Miyabe C, Miyabe $Y$, Miura NN, Takahashi K, Terashima Y, Toda E, Honda F, Morio T, Yamagata N, Ohno N, Shudo K, Suzuki J, Isobe M, Matsushima K, Tsuboi R, Miyasaka N, Nanki T. Am80, a retinoic acid receptor agonist, ameliorates murine vasculitis through the suppression of neutrophil migration and activation. Arthritis Rheum., 65, 503-512 (2013).

19) Martinez HG, Quinones MP, Jimenez F, Estrada C, Clark KM, Suzuki K, Miura N, Ohno N, Ahuja SK, Ahuja SS. Important role of CCR2 in a murine model of coronary vasculitis. BMC Immunol., 13, 56 (2012).

20) Takahashi K, Oharaseki T, Yokouchi Y, Miura NN, Ohno N, Okawara AI, Murata H, Naoe S, Suzuki K. Administration of human immunoglobulin suppresses development of murine systemic vasculitis induced with Candida albicans water-soluble fraction: an animal model of Kawasaki disease. Mod. Rheumatol., 20, 160-167 (2010).

21) Miura NN, Komai M, Adachi Y, Osada N, Kameoka Y, Suzuki K, Ohno N. IL-10 is a negative regulatory factor of CAWS-vasculitis in CBA/J mice as assessed by comparison with Bruton's tyrosine kinase-deficient CBA/N mice. J. Immunol., 183, 3417-3424 (2009).

22) Hirata $N$, Ishibashi $K$, Ohta $S$, Hata $S$, Shinohara H, Kitamura M, Miura N, Ohno N. Histopathological examination and analysis of mortality in DBA/2 mouse vasculitis induced with CAWS, a watersoluble extracellular polysaccharide fraction obtained from Candida albicans. Yakugaku Zasshi, 126, 643-650 (2006).

23) Hirata N, Ishibashi K, Sato W, Nagi-Miura N, Adachi Y, Ohta S, Ohno N. beta-mannosyl linkages inhibit CAWS arteritis by negatively regulating dectin-2-dependent signaling in spleen and dendritic cells. Immunopharmacol. Immunotoxicol., 35, 594-604 (2013).

24) Shinohara $H$, Nagi-Miura $N$, Ishibashi $K$, Adachi $Y$, IshidaOkawara A, Oharaseki T, Takahashi K, Naoe S, Suzuki K, Ohno N. Beta-mannosyl linkages negatively regulate anaphylaxis and vasculitis in mice, induced by CAWS, fungal PAMPS composed of mannoprotein-beta-glucan complex secreted by Candida albicans. Biol. Pharm. Bull., 29, 1854-1861 (2006).

25) Nakamura J, Watanabe S, Kimura H, Kobayashi M, Karasawa T, Kamata R, Usui-Kawanishi F, Sadatomo A, Mizukami H, NagiMiura N, Ohno N, Kasahara T, Minota S, Takahashi M. Adenoassociated virus vector-mediated interleukin-10 induction prevents vascular inflammation in a murine model of Kawasaki disease. Sci. Rep., 8, 7601 (2018).

26) Ohno N. Chemistry and biology of angiitis inducer, Candida albicans water-soluble mannoprotein-beta-glucan complex (CAWS). Microbiol. Immunol., 47, 479-490 (2003). 
27) Katayama M, Ota K, Nagi-Miura N, Ohno N, Yabuta N, Nojima H, Kumanogoh A, Hirano T. Ficolin-1 is a promising therapeutic target for autoimmune diseases. Int. Immunol., 31, 23-32 (2019).

28) Nagi-Miura N, Okuzaki D, Torigata K, Sakurai MA, Ito A, Ohno $\mathrm{N}$, Nojima H. CAWS administration increases the expression of interferon gamma and complement factors that lead to severe vasculitis in DBA/2 mice. BMC Immunol., 14, 44 (2013).

29) Tada R, Yamanaka D, Nagi-Miura N, Adachi Y, Ohno N. Vasculitis and anaphylactoid shock induced in mice by cell wall extract of the fungus Candida metapsilosis. Pol. J. Microbiol., 63, 223-230 (2014).

30) Tada R, Takano Y, Murakami H, Ishibashi K, Nagi-Miura N, Adachi Y, Ohno N. Vasculitis and anaphylactoid shock in mice induced by the polysaccharide fraction secreted into culture supernatants by the fungus Candida metapsilosis. Microbiol. Immunol., 55, 357-365 (2011).

31) Tada R, Nagi-Miura N, Adachi Y, Ohno N. The influence of culture conditions on vasculitis and anaphylactoid shock induced by fungal pathogen Candida albicans cell wall extract in mice. Microb. Pathog., 44, 379-388 (2008).

32) Hirata N, Ishibashi K, Usui T, Yoshioka J, Hata S, Adachi Y, NagiMiura N, Ohta S, Ohno N. A model of left ventricular dysfunction complicated by CAWS arteritis in DBA/2 mice. Int. J. Vasc. Med., 2012, 570297 (2012).

33) Yanai C, Tanaka H, Ishibashi K, Adachi Y, Yamanaka D, Ohnishi H, Nagi-Miura N, Ohno N. Application of heat degradation method to prepare polysaccharides from the cell wall of yeast like fungi, Candida. Pharmacometrics, 96, 85-92 (2019).

34) Yanai C, Ishibashi K, Adachi Y, Yamanaka D, Nagi-Miura N, Ohno N. Stability of Candida mannan to sodium hypochlorite oxidation assessed by CAWS vasculitis. Pharmacometrics, 97, 83-90 (2019).

35) Kasper L, Seider K, Gerwien F, Allert S, Brunke S, Schwarzmuller T, Ames L, Zubiria-Barrera C, Mansour MK, Becken U, Barz D, Vyas JM, Reiling N, Haas A, Haynes K, Kuchler K, Hube B. Identification of Candida glabrata genes involved in $\mathrm{pH}$ modulation and modification of the phagosomal environment in macrophages. PLOS ONE, 9, e96015 (2014).

36) Mille C, Fradin C, Delplace F, Trinel PA, Masset A, Francois N, Coddeville B, Bobrowicz P, Jouault T, Guerardel Y, Wildt S, Janbon G, Poulain D. Members 5 and 6 of the Candida albicans BMT family encode enzymes acting specifically on beta-mannosylation of the phospholipomannan cell-wall glycosphingolipid. Glycobiology, 22, 1332-1342 (2012).

37) Sen M, Shah B, Rakshit S, Singh V, Padmanabhan B, Ponnusamy M, Pari K, Vishwakarma R, Nandi D, Sadhale PP. UDP-glucose 4, 6-dehydratase activity plays an important role in maintaining cell wall integrity and virulence of Candida albicans. PLoS Pathog., 7, e1002384 (2011).

38) Cantero PD, Ernst JF. Damage to the glycoshield activates PMTdirected $O$-mannosylation via the Msb2-Cek1 pathway in Candida albicans. Mol. Microbiol., 80, 715-725 (2011).

39) Castillo L, MacCallum DM, Brown AJ, Gow NA, Odds FC. Differential regulation of kidney and spleen cytokine responses in mice challenged with pathology-standardized doses of Candida albicans mannosylation mutants. Infect. Immun., 79, 146-152 (2011).

40) Mora-Montes HM, Bates S, Netea MG, Castillo L, Brand A, Buurman ET, Diaz-Jimenez DF, Jan Kullberg B, Brown AJ, Odds FC, Gow NA. A multifunctional mannosyltransferase family in Candida albicans determines cell wall mannan structure and host-fungus interactions. J. Biol. Chem., 285, 12087-12095 (2010).

41) Mille C, Bobrowicz P, Trinel PA, Li H, Maes E, Guerardel Y, Fradin C, Martinez-Esparza M, Davidson RC, Janbon G, Poulain $\mathrm{D}$, Wildt S. Identification of a new family of genes involved in beta-1,2-mannosylation of glycans in Pichia pastoris and Candida albicans. J. Biol. Chem., 283, 9724-9736 (2008).

42) Corbucci C, Cenci E, Skrzypek F, Gabrielli E, Mosci P, Ernst JF,
Bistoni F, Vecchiarelli A. Immune response to Candida albicans is preserved despite defect in $O$-mannosylation of secretory proteins. Med. Mycol., 45, 709-719 (2007).

43) Rouabhia M, Schaller M, Corbucci C, Vecchiarelli A, Prill SK, Giasson L, Ernst JF. Virulence of the fungal pathogen Candida albicans requires the five isoforms of protein mannosyltransferases. Infect. Immun., 73, 4571-4580 (2005).

44) Prill SK, Klinkert B, Timpel C, Gale CA, Schroppel K, Ernst JF. PMT family of Candida albicans: five protein mannosyltransferase isoforms affect growth, morphogenesis and antifungal resistance. Mol. Microbiol., 55, 546-560 (2005).

45) Munro CA, Bates S, Buurman ET, Hughes HB, Maccallum DM, Bertram G, Atrih A, Ferguson MA, Bain JM, Brand A, Hamilton S, Westwater C, Thomson LM, Brown AJ, Odds FC, Gow NA. Mntlp and Mnt2p of Candida albicans are partially redundant alpha-1,2mannosyltransferases that participate in $O$-linked mannosylation and are required for adhesion and virulence. J. Biol. Chem., 280, 1051-1060 (2005)

46) Weber Y, Prill SK, Ernst JF. Pmt-mediated O mannosylation stabilizes an essential component of the secretory apparatus, Sec20p, in Candida albicans. Eukaryot. Cell, 3, 1164-1168 (2004).

47) Mille C, Janbon G, Delplace F, Ibata-Ombetta S, Gaillardin C, Strecker G, Jouault T, Trinel PA, Poulain D. Inactivation of CaMIT1 inhibits Candida albicans phospholipomannan beta-mannosylation, reduces virulence, and alters cell wall protein beta-mannosylation. J. Biol. Chem., 279, 47952-47960 (2004).

48) Thomson LM, Bates S, Yamazaki S, Arisawa M, Aoki Y, Gow NA. Functional characterization of the Candida albicans MNT1 mannosyltransferase expressed heterologously in Pichia pastoris. J. Biol. Chem., 275, 18933-18938 (2000).

49) Timpel C, Strahl-Bolsinger S, Ziegelbauer K, Ernst JF. Multiple functions of Pmtlp-mediated protein $O$-mannosylation in the fungal pathogen Candida albicans. J. Biol. Chem., 273, 20837-20846 (1998).

50) Buurman ET, Westwater C, Hube B, Brown AJ, Odds FC, Gow NA. Molecular analysis of CaMntlp, a mannosyl transferase important for adhesion and virulence of Candida albicans. Proc. Natl. Acad. Sci. U.S.A., 95, 7670-7675 (1998).

51) Dambuza IM, Brown GD. C-type lectins in immunity: recent developments. Curr. Opin. Immunol., 32, 21-27 (2015).

52) Kerscher B, Willment JA, Brown GD. The Dectin-2 family of Ctype lectin-like receptors: an update. Int. Immunol., 25, 271-277 (2013).

53) Vautier S, MacCallum DM, Brown GD. C-Type lectin receptors and cytokines in fungal immunity. Cytokine, 58, 89-99 (2012).

54) Saijo S, Iwakura Y. Dectin-1 and Dectin-2 in innate immunity against fungi. Int. Immunol., 23, 467-472 (2011).

55) Drummond RA, Saijo S, Iwakura Y, Brown GD. The role of Syk/ CARD9 coupled C-type lectins in antifungal immunity. Eur. J. Immunol., 41, 276-281 (2011).

56) Silva LN, de Mello TP, de Souza Ramos L, Branquinha MH, Dos Santos ALS. New and promising chemotherapeutics for emerging infections involving drug-resistant non-albicans Candida species. Curr. Top. Med. Chem., 19, 2527-2553 (2019).

57) Kolaczkowska A, Kolaczkowski M. Drug resistance mechanisms and their regulation in non-albicans Candida species. J. Antimicrob. Chemother., 71, 1438-1450 (2016).

58) Whibley N, Gaffen SL. Beyond Candida albicans: Mechanisms of immunity to non-albicans Candida species. Cytokine, 76, 42-52 (2015).

59) Opulente DA, Langdon QK, Buh KV, Haase MAB, Sylvester K, Moriarty RV, Jarzyna M, Considine SL, Schneider RM, Hittinger CT. Pathogenic budding yeasts isolated outside of clinical settings. FEMS Yeast Res., 19, 19 (2019).

60) Douglass AP, Offei B, Braun-Galleani S, Coughlan AY, Martos AAR, Ortiz-Merino RA, Byrne KP, Wolfe KH. Population genom- 
ics shows no distinction between pathogenic Candida krusei and environmental Pichia kudriavzevii: one species, four names. PLOS Pathog., 14, e1007138 (2018).

61) Nagarathnamma T, Chunchanur SK, Rudramurthy SM, Vineetha KR, Ramamurthy K, Joseph J, Ambica R. Outbreak of Pichia kudriavzevii fungaemia in a neonatal intensive care unit. J. Med. Microbiol., 66, 1759-1764 (2017).

62) Kurtzman CP, Smiley MJ. Heterothallism in Pichia kudriavzevii and Pichia terricola. Antonie van Leeuwenhoek, 42, 355-363 (1976).

63) Kurtzman CP, Smiley MJ, Johnson CJ. Emendation of the genus Issatchenkia kudriavzev and comparison of species by deoxyribonucleic acid reassociation, mating reaction, and ascospore ultrastructure. Int. J. Syst. Bacteriol., 1980, 503-513 (1980).

64) Shibata N, Kobayashi H, Suzuki S. Immunochemistry of pathogenic yeast, Candida species, focusing on mannan. Proc. Jpn. Acad., Ser.
B, Phys. Biol. Sci., 88, 250-265 (2012).

65) Nelson RD, Shibata N, Podzorski RP, Herron MJ. Candida mannan: chemistry, suppression of cell-mediated immunity, and possible mechanisms of action. Clin. Microbiol. Rev., 4, 1-19 (1991).

66) Kuraoka T, Ishiyama A, Oyamada H, Ogawa Y, Kobayashi H. Presence of $O$-glycosidically linked oligosaccharides in the cell wall mannan of Candida krusei purified with Benanomicin A. FEBS Open Bio, 9, 129-136 (2019).

67) Kogan G, Pavliak V, Sandula J, Masler L. Novel structure of the cellular mannan of the pathogenic yeast Candida krusei. Carbohydr. Res., 184, 171-182 (1988).

68) Nishikawa A, Shinoda T, Fukazawa Y. Immunochemical determinant and serological specificity of Candida krusei. Mol. Immunol., 19, 367-373 (1982). 